\title{
Isolation, Analytical Measurements, and Cell Line Studies of the Iron-Bryostatin-1 Complex
}

Sydney Plummer ${ }^{\mathrm{a}}$, Thomas Manning ${ }^{\mathrm{a} *}$, Tess Baker ${ }^{\mathrm{a}}$, Tysheon McGreggor ${ }^{\mathrm{a}}$, Mehulkumar Patel ${ }^{\mathrm{a}}$, Greg Wylie ${ }^{\mathrm{b}}$, Dennis Phillips ${ }^{\mathrm{c}}$

${ }^{a}$ Department of Chemistry, Valdosta State University, Valdosta, GA 31698

${ }^{\mathrm{b}}$ NMR Facility, Department of Chemistry, Texas A\&M, College Station, TX 77843

${ }^{\mathrm{c}}$ PAMS Facility, Department of Chemistry, University of Georgia, Athens, GA 30602

\begin{abstract}
Bryostatin-1 is a marine natural product that has demonstrated medicinal activity in preclinical and clinical trials for the treatment of cancer, Alzheimer's disease, effects of stroke, and HIV. In this study, iron-bryostatin-1 was obtained using a pharmaceutical aquaculture technique developed by our lab that cultivates marine bacteria for marine natural product extraction. Analytical measurements ${ }^{1} \mathrm{H}$ and ${ }^{13} \mathrm{C} \mathrm{NMR}$, mass spectrometry, and flame atomic absorption were utilized to confirm the presence of an iron-bryostatin-1 complex. The iron-bryostatin-1 complex produced was then tested against the National Cancer Institute's 60 cell line panel. Adding iron to bryostatin-1 lowered the anti-cancer efficacy of the compound.
\end{abstract}

*Corresponding Author: tmanning@valdosta.edu

Keywords: bryostatin, synthesis, cancer, cell line, iron, aquaculture, Candidatus Endobugula sertula, Bugula neritina 
In 1968, nearly three hundred marine specimens were collected from the Gulf Coast of Florida and screened for medicinal activity by the National Cancer Institute (NCI) and its collaborators. From this collection, extracts obtained from the sessile, filter feeding bryozoan Bugula neritina demonstrated medicinal activity. In the 1980's Cherry Herald, a scientist working with George Pettit at Arizona State University, isolated the first milligram quantities of the bryozoan extract, bryostatin-1, from a five hundred kilogram collection of $B$. neritina. The compound exhibited significant activity against murine P388 lymphocytic leukemia, and its structure was determined by crystallographic and spectroscopic techniques (see figure 1). ${ }^{1-2} \mathrm{After}$ the first structural determination of bryostatin-1, at least nineteen additional structural variations of bryostatin were identified from the bryozoan. ${ }^{3}$ Davidson et al. ${ }^{4}$ provided evidence that bryostatin is biosynthesized from a bacterial symbiont of $B$. neritina rather than produced by the bryozoan itself. It was demonstrated that the proteobacterial symbiont of the bryozoan, Candidatus Endobugula sertula, is capable of producing the compound, and that a reduction of the symbiont bacteria is associated with decreased levels of bryostatin from the host. The study also suggested cloning the genes responsible for production of bryostatin and replicating them in host bacteria as an alternate source of the compound. ${ }^{4}$ Since its initial demonstration of in vitro anticancer activity, bryostatin compounds have undergone studies not only as a cancer treatment, but as a potential therapeutic agent for Alzheimer's disease, effects of stroke and HIV as well. Demand of the macrolid for clinical evaluation remains constant, however techniques for obtaining bryostatins have hindered further development of its therapeutic uses.

Bryostatins serve a key role in regulating the cell cycle by inactivating or activating certain cyclin-dependent kinases, such as CDK2 and Protein Kinase C (PKC), that are 


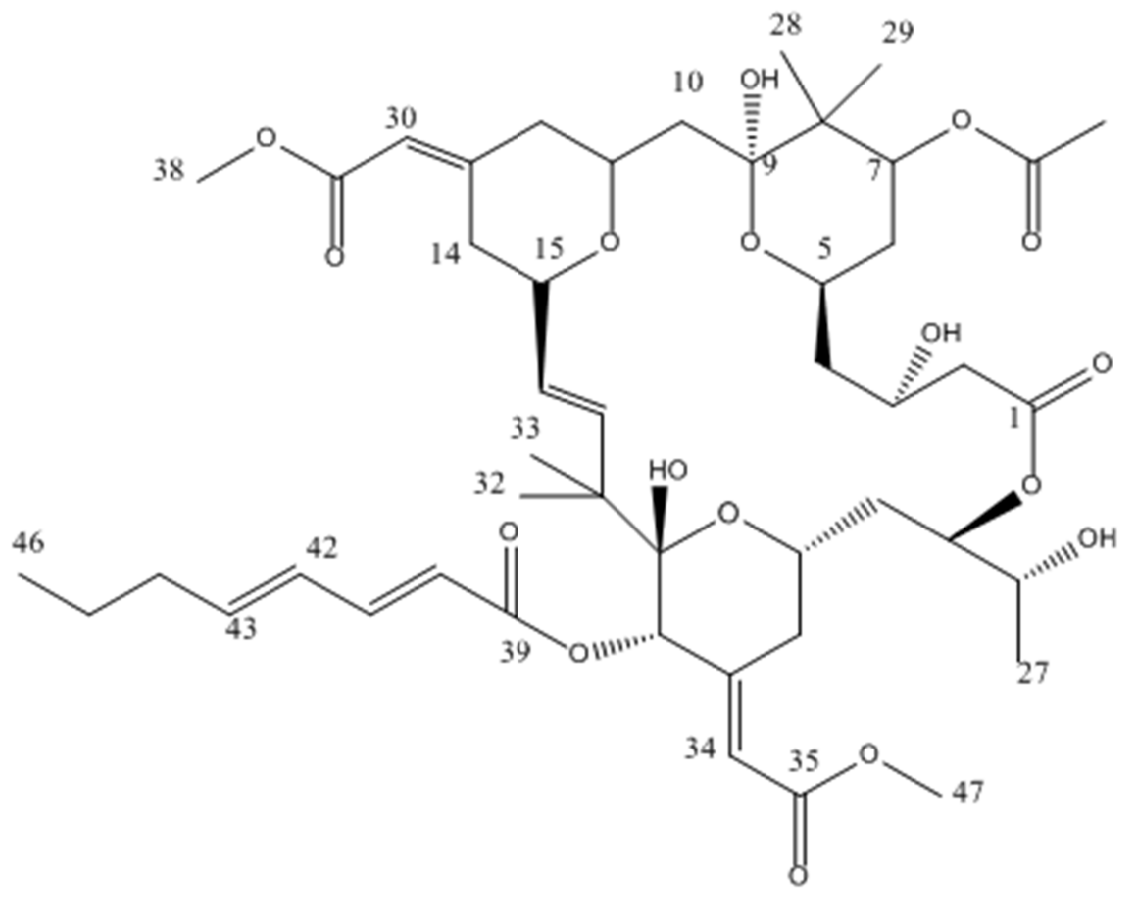

Figure 1. The two dimensional structure of bryostatin-1. $\left(\mathrm{C}_{47} \mathrm{H}_{58} \mathrm{O}_{17} ; 905 \mathrm{~g} / \mathrm{mol}\right)$. The bryophan ring, present in all bryostatin molecules, can bind a host of cations including $\mathrm{Na}^{+}$and $\mathrm{Fe}^{3+}$. 
responsible for cell differentiation and signal transduction. PKCs have a role in cell growth and death with a number of different types of the protein differentiated based on functionality. ${ }^{5-6}$ At sub-nanomolar inhibitory concentrations, the marine based compound binds to the C-terminus region of the PKC active site which ultimately results in auto-phosphorylation, protein translocation, down-regulation, and ubiquitination. ${ }^{5}$ Short term exposure to bryostatin-1 can induce PKC activation and auto-phosphorylation, while prolonged exposure can induce PKC inhibition by depleting the cell. Bryostatin can induce apoptosis by affecting activity of cell cycle regulatory proteins. It has been suggested that medicinal properties of the compound may not be exclusively attributed to PKC binding. ${ }^{6}$

Pre-clinical data indicating that bryostatin-1 improves efficacy of chemotherapy, hinders cancer cell proliferation, induces differentiation, and stimulates apoptosis has resulted in bryostatin-1 being evaluated in phase I and phase II clinical trials as a treatment for melanoma, non-Hodgkin's lymphoma, soft tissue sarcoma, ovarian carcinoma, and other forms of cancer. The findings of these studies and others suggest combination therapy of bryostatin-1 and other agents, including paclitaxel and cytarabine, to be more encouraging for future use of the drug once associated toxicities can be ameliorated. ${ }^{5}$

A phase II clinical trial demonstrated that combination therapy of cisplatin and bryostatin-1 resulted with modest responses in patients with persistent or recurrent ovarian cancer. However, the grade three and four toxicities associated were detrimental to the therapy, determining that this therapy should not be tested further unless significantly altered. ${ }^{7}$ Results from a phase II clinical trial of bryostatin-1 treating non-Hodgkin's lymphoma patients demonstrated that the therapy was non-efficacious and too toxic, with myalgia and phlebitis being the primary side effects. Explanation for the lack of efficacy was unclear, however 
Blackhall et al. ${ }^{8}$ argued pre-clinical data of bryostatin-1 synergism with cytotoxic agents and cytokines warrant further evaluation of combination therapies with bryostatin- $1 .{ }^{8} \mathrm{~A}$ phase II clinical trial combining bryostain-1 and interleukin-2 to treat renal cell carcinoma resulted with common grade three toxicities and only a 3.2 percent response rate among patients, rendering no further need for trials using this regimen. ${ }^{9}$ A phase II clinical study by Madhusudan et al. ${ }^{10}$ found that bryostatin-1 alone was not effective in treating advanced renal cancer, but it was suggested that combination therapy with bryostatin-1 may be a better option to assess. ${ }^{10}$ Combining bryostatin-1 with pacliataxel increased response rates compared to paclitaxel alone in treating advanced gastric or gastroesophageal junction adenocarcinoma (i.e. 29 percent response rate compared to 17 percent response rate). However, over half of patients experienced myalgia. The data warrant further studies if bryostatin-1 induced myalgia can be controlled. ${ }^{11}$

Bryostatin-1 has also been studied for the treatment of conditions associated with Alzheimer's disease (AD) through a variety of proposed mechanisms. Several animal models show that PKC activation is involved in normal memory processes but is defective in AD. In vivo data has shown that bryostatin-1 could be a potential AD treatment via modulation of the alpha secretase pathway, which is induced by PKC activation, and to be preventative for toxic fragment accumulation effects. Bryostatin-1 was also associated with higher survival rates and longevity in murine models. ${ }^{12}$ Another study demonstrated that the loss of neuronal synapses, a characteristic of $\mathrm{AD}$, can be prevented by up-regulation and prevention of PKC $\alpha$ and PKC $\varepsilon$ suppression by bryostatin- 1 in murine models. ${ }^{13}$ A recent study demonstrated that bryostatin-1 had significant impacts on a patient with advanced, early onset AD including improvements in speech, ability to focus, and muscular control. ${ }^{14}$ 
Pre-clinical data has suggested that bryostatin-1 could be effective in preventing and treating side effects of stroke. In vivo results demonstrated that bryostatin-1 improved deficiencies in synaptogenesis, neurotropic activity, and spatial learning and memory after ischemic/hypoxic cerebral conditions were induced in aged mice. Data indicate that the drug utilizes certain PKC isozymes to hinder pathophysiological molecular cascades and apoptosis which are activated by cerebral ischemia and hypoxia. ${ }^{15-16}$ Administering bryostatin-1 after acute ischemic strokes has demonstrated improved survival rates and functioning by reducing damage and preventing cerebral tissue from further damage in murine models. ${ }^{17}$

Administration of bryostatin-1 alongside antiretroviral therapy has shown to be a potential method to help eradicate HIV. Bryostatin-1 induces activation of latent reservoirs of the virus, which represent a hindrance in treatment and elimination of HIV. In vitro evaluation of bryostatin-1 demonstrated its ability to inhibit acute HIV-1 infection while inducing latent infections in monocytic and lymphocytic cells by PKC activation. Furthermore, the drug was not toxic towards cells and it did not activate T-cells. ${ }^{18}$ Analogues of bryostatin developed by DeChristopher et al. ${ }^{19}$ were equally or more efficacious than bryostatin in in vitro models, and at dosages that were up to 1,000 fold lower than the HIV drug prostratin. ${ }^{19}$

Trials of in-sea and controlled tank cultivation of B. nertina in Southern California have been evaluated to determine feasibility and cost for commercial extraction and production of bryostatins. In-sea aquaculture proved to be cost-effective for obtaining the marine compound while controlled tank aquaculture was not. Environmental impacts attributed to the artificial systems were not substantial, and wild populations were not affected by in-sea aquaculture systems. However, both the wild and cultivated populations of B. neritina died during unpredictably warm water temperatures due to El Niño currents, demonstrating inconsistent 
productivity due to uncontrollable events which would not be an issue in controlled tank systems. The study noted that logistical and engineering challenges for in-sea aquaculture still present obstacles. ${ }^{20}$ Laboratory studies demonstrated that B. neritina larval production is sensitive to manipulation of light exposure, air exposure, and water flow suggesting higher maintenance for in-tank aquaculture settings and sensitivity to environmental condition changes for in-sea systems for the above three conditions. ${ }^{21}$

There are twenty known forms of bryostatin, with nineteen sharing the same bryophan ring (see figure 1). The macrolid structure of bryostatins presents a challenge to synthetic chemists. The published syntheses of bryostatins can require up to 70 steps and have yet proved to be practical to produce large amounts of the compounds. ${ }^{3}$ The 40 step synthesis of bryostatin2 by Evans et al. ${ }^{22}$ demonstrated a flexible route that could be useful in identifying new bryostatin analogues. ${ }^{22}$ Bryostatin-3 has particularly low yields in natural extractions, and was therefore synthesized by Ohmori et al. ${ }^{23}$ for its potential antitumor activity. ${ }^{23}$ Bryostatin- 9 was synthesized in 42 steps and included 25 linear steps. ${ }^{24}$ In 2008 , Trost et al. ${ }^{25}$ synthesized bryostatin-16 in 39 steps using a palladium mediated technique that synthesized two groups to close the macrocyclic structure. Results suggested analogues of bryostatin could be synthesized using a similar method. ${ }^{25}$ Bryostatin-7 was synthesized in 36 steps by Lu et al. ${ }^{26}$, representing the shortest total synthesis of any bryostatin until Keck et al. ${ }^{27}$ achieved the first total synthesis of bryostatin-1 in 2010 in under 30 steps ${ }^{26-27}$ Currently, organic synthesis is not a viable method to economically produce bryostatins for large scale pharmaceutical use.

Development of bryostatin analogues has been an alternative method for obtaining the medicinal activity of the marine natural product. The approach of Wender and colleagues at Stanford University since the 1980's has used computer modeling and other techniques to 
produce bryostatin analogues designed to have less or no toxicity compared to the original compounds. The analogues have been evaluated with NMR spectroscopy, PKC binding assay, and cancer cell line studies and resulted with data similar to that of the molecules they were derived from. ${ }^{28-29}$ The most prominent analogue they have produced is the picolog (see figure 2) which has demonstrated efficacy in targeting lymphoma in murine models. ${ }^{30}$

Metal ions are vital components in many biological functions such as metabolism, memory formation, and a host of enzymatic reactions. Complexation of metal ions to drugs can be beneficial for diversifying application and improving efficacy of the original drugs. For example, the antibiotic belomycin contains nitrogen atoms that naturally bind to iron, giving it redox potential and allowing the compound to cleave DNA. This transforms the functional use of the compound, changing the antibiotic properties into anti-cancer properties. ${ }^{31}$ Copper is another trace element that serves as a nutrient for many biological functions and improves the efficacy of NSAIDs, antibiotics and anti-cancer drugs. ${ }^{31}$ Iron oxide nanoparticles have been tested as a drug delivery agent for cancer drugs extensively. ${ }^{32}$

Research with bryostatin from our lab began over fifteen years ago and has been optimized to obtain extractions from natural sources. Measurements using mass spectrometry from fourteen different marine species, as well as sediment and water columns associated with the species, from the Gulf of Mexico suggest that bryostatin itself or bryostatin precursors could be obtained from other sources that are currently identified. ${ }^{33}$ Our group has been developing microbial amplification chambers (MACs) to maximize growth and colonization of marine microbes by altering the environments of chambers using chemical species and other materials for cultivation of bryostatin. The process developed involves a colonization step, an 


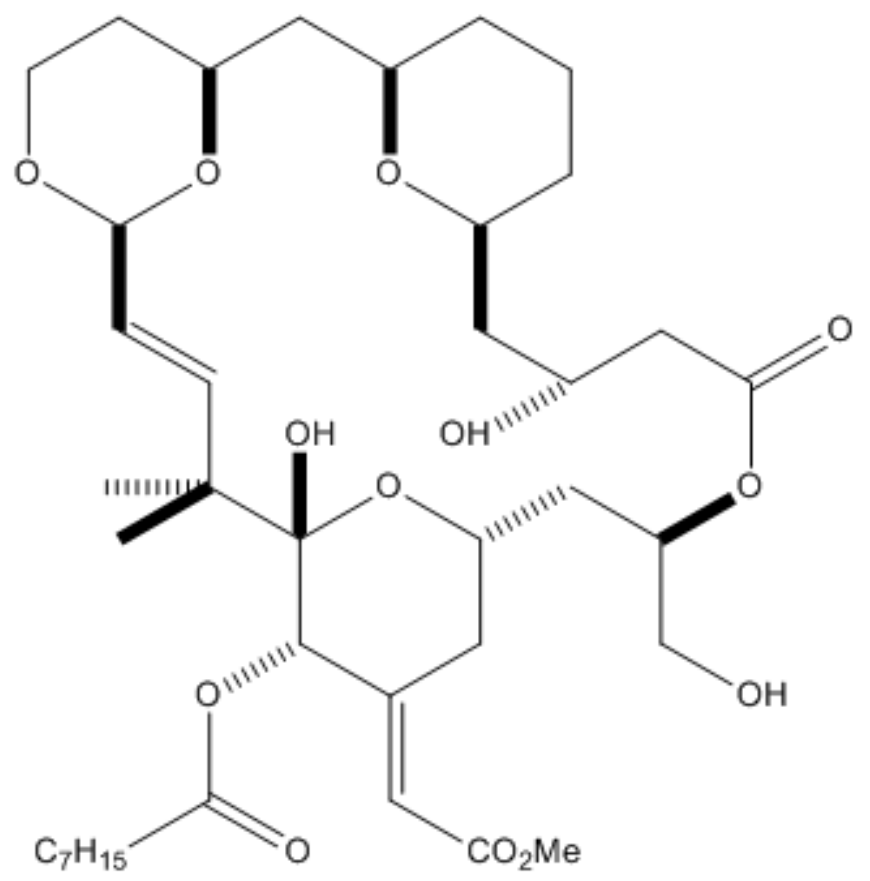

Figure 2. The two dimensional structure of the bryostatin analogue picolog. 
amplification phase, and an extraction step. ${ }^{34}$ Variations of bryostatin structures derived from changes induced by environmental chemical conditions were identified using FT-ICR, MALDITOF-MS, UV/Vis absorbance spectroscopy, and molecular modeling to improve recognition of bryostatin compounds after the extraction step. ${ }^{35}$ Another study by Manning et al. ${ }^{36}$ using computational methods produced geometric data that indicated iron-bryostatin-1, which naturally binds in the environment, increases water solubility and stabilizes the molecule. ${ }^{36}$ These results suggest that iron-bryostatin-1 can improve chemical parameters for drugs administered orally, as outlined by Lipinski's Rule of Five, compared to pure bryostatin-1 which led to the implication of this study. ${ }^{36}$

The iron-bryostatin-1 complex described in this study was synthesized using a pharmaceutical aquaculture technique developed from this lab. ${ }^{34}$ Marine sediment from Alligator Point Harbor (FL) was taken from a depth of six to eight inches below the surface. The sediment samples were then treated with nutrients including sucrose, starch, vitamins, amino acids, proteins, phosphates, nitrates and other organic and inorganic substances. In addition, inorganics such as limestone and iron rich fertilizer were added to the sediment. The total amount of nutrients added to the sediment was approximately 0.5 percent (by mass) of nutrients, with 85.0 percent of that nutrient mass being sucrose. Perforated five gallon containers were utilized to hold the sand-nutrient mixture for approximately one month in the Gulf of Mexico. The locations were selected based on proximity to B. neritina colonies, an indicator for the presence of Candidatus E. sertula. The containers were placed in a 4.5 meter runway at the Florida State University Coastal \& Marine Lab that had filtered (5 micrometer filter) seawater constantly flowing. Additional sources of iron were added to the runways containing the seawater and sediment samples including approximately $0.5-1.5 \mathrm{~kg}$ of steel wool and approximately $9 \mathrm{~kg}$ of 
iron bars, or rebar. Different quantities of sand, ranging from 100 to 1,000 grams were removed from the buckets and immersed in a toluene-ethanol solvent for forty-eight hours. The use of an ethanol-toluene solvent was based on its use in cellulose extraction experiments. ${ }^{37}$ The solvent was dried and extracted with dichloromethane, and then evaporated again. The dried sample was mixed with silica and separated over a silica column using acetonitrile as the mobile phase. A silica column approximately $38 \mathrm{~cm}$ high with a frit membrane and a $6 \mathrm{~mm}$ inch sand bed held the silica. The raw extract was mixed with silica in a dichloromethane or methanol solution, allowed to dry, and placed on top of the silica bed. A typical extraction would produce up to twenty-five to fifty milligrams of raw iron-bryostatin-1 per kilogram, with an excess of iron. The samples analyzed and discussed in this study were collected from February to June 2011.

Table 1 compares ${ }^{1} \mathrm{H}$ and ${ }^{13} \mathrm{C}$ NMR data of bryostatin-1 found in the literature with two samples of iron-bryostatin-1 collected at different times from the runway at FSU Coastal \& Marine Lab. ${ }^{38-39}$ Thirteen of the forty-seven ${ }^{13} \mathrm{C}$ NMR spectral features are not identifiable in the samples, which is attributed to the impact of the paramagnetic effect of the iron atom. The other atoms were sufficiently removed from the iron binding site to the marine natural product demonstrating that there was little or no shift in their position. The ${ }^{1} \mathrm{H} N M R$, with sixty-eight ${ }^{1} \mathrm{H}$ atoms, contained significant splitting and shifting, proving to be difficult to decipher when bound to the paramagnetic ion (see table 1). Metal-pi bonding by the Fe cation to the double bonds on

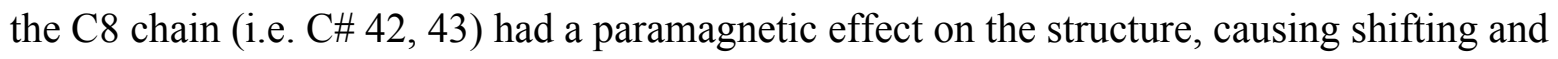
disappearance of specific NMR spectral features (see table 1). In addition to one dimensional NMR, two dimensional techniques Heteronuclear Single Quantum Coherence (HSQC) and 
Table 1. Column 1 gives the carbon numbers correlated with the bryostatin-1 structure in Figure 1. Column 2 gives the ${ }^{1} \mathrm{H}$ NMR literature values from Petit et al. ${ }^{38}$ Column 3 and 4 gives ${ }^{1} \mathrm{H}$ NMR positions for Fe-bryostatin-1 collected from the runway at FSU Coastal \& Marine Lab in February and June 2011, respectively. Column 5 gives the ${ }^{13} \mathrm{C}$ NMR values from Petit et al. ${ }^{39}$ for pure bryostatin, and column 6 gives experimental results on the June 2011 sample. ${ }^{38}$

\begin{tabular}{|c|c|c|c|c|c|}
\hline 1 & 2 & 3 & 4 & 5 & 6 \\
\hline $\begin{array}{c}\text { Carbon } \\
\text { Atom }\end{array}$ & $\begin{array}{r}{ }^{1} \mathrm{H} \text { NMR of } \\
\text { bryostatin-1 }\end{array}$ & $\begin{array}{c}{ }^{1} \text { H NMR } \\
\text { (sample 1) }\end{array}$ & $\begin{array}{c}\text { 1H NMR } \\
\text { (sample 2) }\end{array}$ & $\begin{array}{c}{ }^{13} \mathrm{C} \text { NMR } \\
\text { bryostatin-1 }\end{array}$ & $\begin{array}{l}{ }^{13} \mathrm{C} \text { NMR } \\
\text { (sample 1) }\end{array}$ \\
\hline 1 & & & & 172.29 & 173.041 \\
\hline 2 & 2.45 & 1.6351 & 2.44179 & 44.29 & 29.6655 \\
\hline 3 & 4.09 & 3.98106 & 3.11685 & 71.62 & 69.4261 \\
\hline 4 & $1.55,1.95$ & 1.18759 & 1.2848 & 31.42 & 31.5576 \\
\hline 5 & 4.19 & 3.97886 & 4.13028 & 73.73 & 76.8991 \\
\hline 6 & $1.4,1.75$ & 0.884605 & 1.2848 & 35.09 & 33.8769 \\
\hline 7 & 5.15 & & 4.31168 & 73.1 & \\
\hline 8 & & & & 41.1 & 28.872 \\
\hline 9 & & & & 101.94 & \\
\hline 10 & $2.1-2.2$ & 1.61898 & 1.73012 & 36.04 & 33.8731 \\
\hline 11 & $\sim 3.95$ & 2.32211 & 3.07168 & 68.50 & 66.6796 \\
\hline 12 & $2.1-2.2$ & 1.60482 & 2.31704 & 36.56 & 28.8682 \\
\hline 13 & & & & 157.18 & \\
\hline 14 & $1.9, \sim 2.0$ & 1.20004 & 1.61586 & 40.00 & 54.1254 \\
\hline 15 & 4.08 & 3.96763 & 3.98453 & 70.22 & 67.1068 \\
\hline 16 & 5.3 & 4.27549 & 4.15372 & 139.24 & \\
\hline 17 & 5.76 & 5.25279 & 4.16544 & 129.66 & 129.599 \\
\hline
\end{tabular}




\begin{tabular}{|c|c|c|c|c|c|}
\hline 18 & & & & 44.94 & 54.1177 \\
\hline 19 & & & & 99.11 & \\
\hline 20 & 5.16 & 4.21446 & 4.68888 & 79.13 & \\
\hline 21 & & & 1.33559 & 152.08 & 157.70 \\
\hline 22 & $\sim 1.90$ & 1.24764 & 1.25697 & 35.94 & \\
\hline 23 & $\sim 3.65$ & 1.65756 & & 74.32 & \\
\hline 24 & 1.95 & 1.31283 & 1.33559 & 40.00 & \\
\hline 25 & 5.19 & 4.20665 & 4.14175 & 71.55 & 76.8991 \\
\hline 26 & 3.73 & 1.68686 & 2.98135 & 68.54 & 66.6796 \\
\hline 27 & 1.23 & 0.872398 & 1.25697 & 21.90 & 22.5167 \\
\hline 28 & 1.13 & 0.858482 & 0.903211 & 16.86 & \\
\hline 29 & 0.98 & 0.0623347 & 0.893201 & 16.90 & 12.266 \\
\hline 30 & 5.66 & 4.29966 & 4.28824 & 114.15 & \\
\hline 31 & & & & 167.06 & \\
\hline 32 & 0.98 & & 0.888806 & $24.60(21.1)$ & 22.6426 \\
\hline 33 & 0.92 & & 0.888806 & $24.60(21.11)$ & 13.9642 \\
\hline 34 & 5.98 & 5.37218 & 2.90347 & 119.71 & \\
\hline 35 & & & & 166.80 & 172.614 \\
\hline 36 & & & & 51.02 & 62.018 \\
\hline 37 & 2.05 & 1.48446 & 1.49989 & 33.4 & 33.0034 \\
\hline 38 & 3.68 & & 2.98135 & 51.65 & 54.1216 \\
\hline 39 & & & & 171.08 & \\
\hline
\end{tabular}




\begin{tabular}{|c|c|c|c|c|c|}
\hline $\mathbf{4 0}$ & 5.80 & 5.33458 & 5.26261 & 119.6 & 123.393 \\
\hline $\mathbf{4 1}$ & 7.26 & 7.2594 & 8.0949 & 146.39 & \\
\hline $\mathbf{4 2}$ & 6.16 & 6.09216 & 5.34464 & 128.49 & 129.599 \\
\hline $\mathbf{4 3}$ & 6.16 & 6.05944 & 7.28093 & 145.42 & \\
\hline $\mathbf{4 4}$ & $\sim 2.15$ & 1.51327 & 2.31704 & 35.09 & 33.8731 \\
\hline $\mathbf{4 5}$ & 1.42 & 0.87899 & 1.25697 & 24.66 & 28.872 \\
\hline $\mathbf{4 6}$ & 0.90 & & 0.884656 & 13.68 & 13.9642 \\
\hline $\mathbf{4 7}$ & 3.64 & & & 51.02 & 61.018 \\
\hline
\end{tabular}


Correlation Spectroscopy (COSY) were obtained to identify carbon and hydrogen positions on different samples. MALDI-TOF-MS and LC-MS were used to confirm that iron-bryostatin-1 were present in the sample. Spectral features with peaks that match those of the iron isotopes at approximately 960 m/z (Fe-bryostatin-1), 978 m/z (Fe- $\mathrm{H}_{2} \mathrm{O}$-bryostatin-1) and 983 (Fe-Nabryostatin-1) were consistent features. Figure 3 depicts an LC-MS analysis showing the $927 \mathrm{~m} / \mathrm{z}$ spectra feature that corresponds to the sodium adduct of bryostatin- $1\left[\mathrm{Na}-\mathrm{C}_{47} \mathrm{H}_{68} \mathrm{O}_{17}\right]$, which was present in much lower quantities than the iron-bryostatin-1 complex. Figure 4 depicts an LCMS showing a trace of the iron-bryostatin- 1 complex at $978.40 \mathrm{~m} / \mathrm{z}$. Attempts to remove the iron using chelating agents such as EDTA and DTPA were unsuccessful, although they did reduce the amount of excess iron present slightly, suggesting the stability constant was greater than that of iron-DTPA and iron-EDTA. Flame atomic absorption was utilized to quantitate the amount of iron present in samples. The flash column was approximately fifteen inches high. All solutions were dissolved in nitric acid, heated, filtered and diluted. Iron(III) chloride dissolved in $0.02 \mathrm{M}$ $\mathrm{HCl}$ was used as a stock solution for Perkin-Elmer flame atomic absorption system that utilized a single element iron hollow cathode lamp as a light source. Through the extraction process involving solvents, only material that was dissolved or suspended after a period of time advanced to the next step. Samples consistently demonstrated the ratio of iron to bryostatin $\left[\frac{\mathrm{Fe}}{\mathrm{bryostatin}-1}\right]$ varying from approximately 0.8 to 1.21 . The samples tested in this study (see table 1 sample 1 and 2) had a ratio of $0.96\left[\frac{\mathrm{Fe}}{\text { bryostatin-1 }}\right]\left(\mathrm{Fe}(\mathrm{II}) \log \beta_{101}=16.5 ; \mathrm{Fe}(\mathrm{III}) \log \beta_{101}=28.6\right)$.

Table 2 provides the data results from the National Cancer Institute's single dose 60 cell line panel for both pure bryostatin- 1 and the iron-bryostatin- 1 complex. The pure bryostatin- 1 cell line values were taken from NCI's Developmental Therapeutics Program PUBLIC 


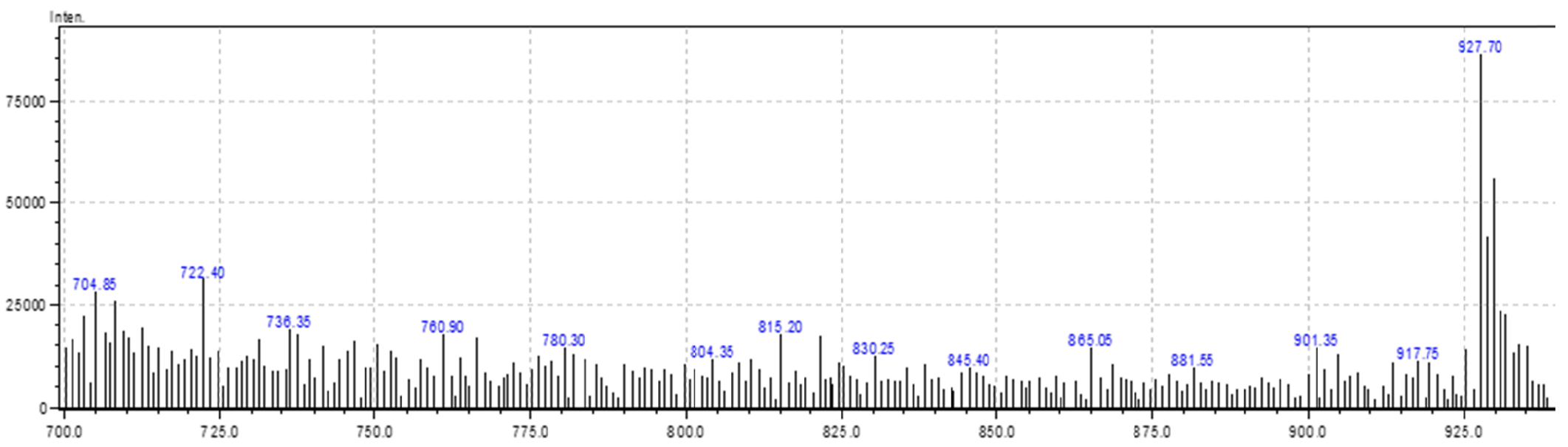

Figure 3. LC-MS that shows the $927 \mathrm{~m} / \mathrm{z}$ spectra feature corresponds to the sodium adduct of bryostatin-1 [ $\mathrm{Na}-\mathrm{C}_{47} \mathrm{H}_{68} \mathrm{O}_{17}$ ]. 


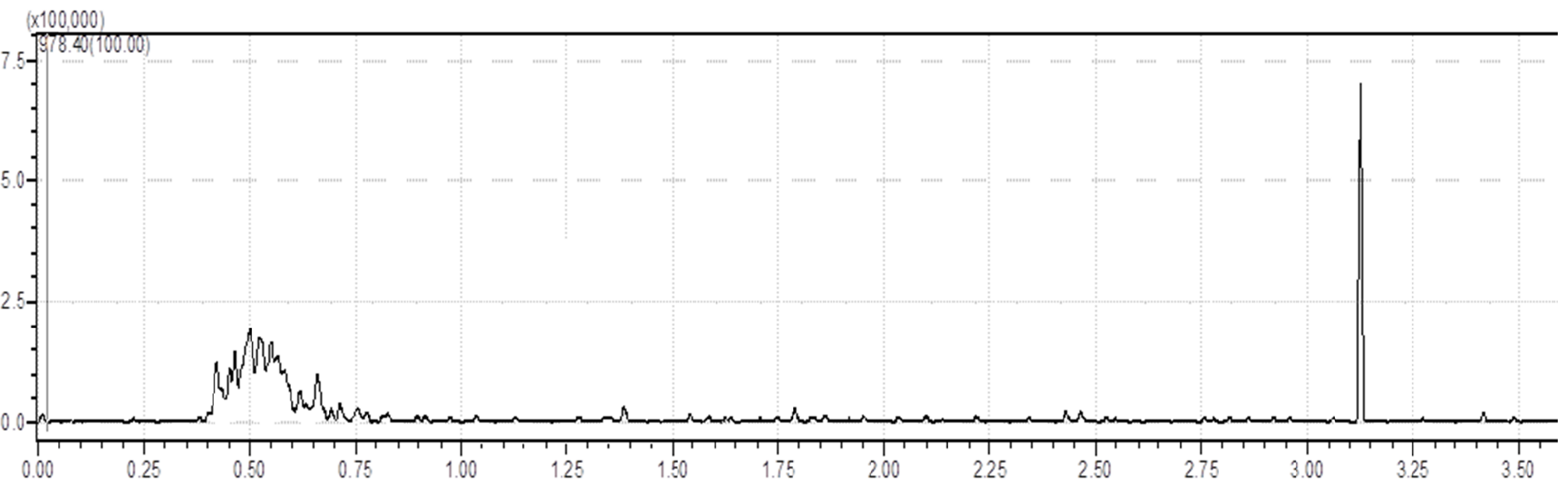

Figure 4. $\mathrm{LC}-\mathrm{MS}$ selected ion chromatogram of $978.4 \mathrm{~m} / \mathrm{z}$ corresponding to $\mathrm{Fe}-\mathrm{H}_{2} \mathrm{O}$-bryostatin$1\left[\mathrm{Fe}-\mathrm{nH}_{2} \mathrm{O}-\mathrm{C}_{47} \mathrm{H}_{68} \mathrm{O}_{17}\right]$ against time. 
Table 2. The cell growth percentages of bryostatin-1 and iron-bryostatin-1 tested at subnanomolar concentrations against NCI's single dose 60 cell line panel.

\begin{tabular}{|c|c|c|c|}
\hline \multirow[t]{2}{*}{ Cell Panel } & \multirow[t]{2}{*}{ Cell Line } & \multicolumn{2}{|c|}{ Percentage Growth } \\
\hline & & Bryostatin-1 & Iron-bryostatin-1 \\
\hline \multirow[t]{8}{*}{ Leukemia } & CCRF-CEM & 73 & 94.27 \\
\hline & K-562 & 70 & 107.07 \\
\hline & MOLT-4 & 82 & 100.31 \\
\hline & RPMI-8226 & 99 & 97.44 \\
\hline & HL-60 (TB) & 82 & - \\
\hline & SR & 72 & 68.89 \\
\hline & P388 & 73 & - \\
\hline & P388/ADR & 53 & - \\
\hline \multirow{9}{*}{$\begin{array}{l}\text { Non-Small Cell Lung } \\
\text { Cancer }\end{array}$} & A549/ATCC & 80 & 90.32 \\
\hline & HOP-62 & 75 & 92.13 \\
\hline & HOP-92 & 63 & 100.35 \\
\hline & HOP-18 & 85 & - \\
\hline & $\mathrm{NCl}-\mathrm{H} 226$ & 90 & 92.51 \\
\hline & $\mathrm{NCl}-\mathrm{H} 23$ & 100 & 99.77 \\
\hline & $\mathrm{NCl}-\mathrm{H} 322 \mathrm{M}$ & 85 & 110.43 \\
\hline & $\mathrm{NCl}-\mathrm{H} 460$ & 68 & 97.95 \\
\hline & $\mathrm{NCl}-\mathrm{H} 522$ & 99 & 119.93 \\
\hline \multirow[t]{2}{*}{ Small Cell Lung Cancer } & DMS114 & 82 & - \\
\hline & DMS273 & 82 & - \\
\hline \multirow[t]{9}{*}{ Colon Cancer } & COLO205 & 53 & 102.93 \\
\hline & HCC-2998 & 88 & 107.53 \\
\hline & DLD-1 & 99 & - \\
\hline & HCT-116 & 92 & 96.23 \\
\hline & HCT-15 & 100 & 102.37 \\
\hline & HT29 & 89 & 103.15 \\
\hline & KM12 & 100 & 101.51 \\
\hline & SW-620 & 75 & 98.31 \\
\hline & KM2OL2 & 97 & - \\
\hline \multirow{8}{*}{$\begin{array}{l}\text { Central Nervous } \\
\text { System Cancer }\end{array}$} & SF-268 & 103 & 102.78 \\
\hline & SF-295 & 74 & 101.97 \\
\hline & SF-539 & 98 & 98.25 \\
\hline & SNB-19 & 102 & 111.21 \\
\hline & SNB-75 & 75 & 90.46 \\
\hline & SNB-78 & 83 & - \\
\hline & U251 & 98 & 97.32 \\
\hline & XF498 & 83 & - \\
\hline \multirow[t]{5}{*}{ Melanoma } & LOXIMVI & 87 & 81.58 \\
\hline & MALME-3M & 77 & 98.94 \\
\hline & M14 & 95 & 96.09 \\
\hline & MDB-MB-435 & 79 & 106.11 \\
\hline & MDA-N & 95 & - \\
\hline
\end{tabular}




\begin{tabular}{|c|c|c|c|}
\hline & SK-MEL-2 & 95 & - \\
\hline & SK-MEL-5 & 75 & 99.54 \\
\hline & SK-MEL-28 & 77 & 104.5 \\
\hline & UACC-257 & 94 & 114.31 \\
\hline & UACC-62 & 70 & 97.75 \\
\hline \multirow[t]{7}{*}{ Ovarian Cancer } & IGROV1 & 85 & 84.46 \\
\hline & OVCAR-3 & 100 & 108.01 \\
\hline & OVCAR-4 & 85 & 102.18 \\
\hline & OVCAR-5 & 101 & 99.87 \\
\hline & OVCAR-8 & 98 & 105.79 \\
\hline & SK-OV-3 & 89 & 95.84 \\
\hline & $\mathrm{NCl} / \mathrm{ADR}-\mathrm{RES}$ & 99 & - \\
\hline \multirow[t]{8}{*}{ Renal Cancer } & $786-0$ & 85 & 97.31 \\
\hline & A 498 & 75 & 85.71 \\
\hline & $\mathrm{ACHN}$ & 75 & 95.66 \\
\hline & CAKI-1 & 75 & 95.71 \\
\hline & RXF-393 & 82 & 118.35 \\
\hline & SN12C & 96 & 105.15 \\
\hline & TK-10 & 100 & 104.7 \\
\hline & UO-31 & 100 & 71.29 \\
\hline \multirow[t]{2}{*}{ Prostate Cancer } & PC-3 & 75 & 92.63 \\
\hline & DU-145 & 97 & 97.64 \\
\hline \multirow[t]{6}{*}{ Breast Cancer } & MCF7 & 100 & 97.48 \\
\hline & MDA-MB-231/ATCC & 94 & 101.84 \\
\hline & H S578T & 97 & 105.28 \\
\hline & B T-549 & 97 & 96.24 \\
\hline & $\mathrm{T}-47 \mathrm{D}$ & - & 92.77 \\
\hline & MDA-MB-468 & - & 102.07 \\
\hline
\end{tabular}


COMPARE database $(\mathrm{NSC}=339555) .{ }^{40}$ The percentage growth for each compound against various forms of cancer was obtained and averaged. The data demonstrated the average percentage growth was lower for pure bryostatin-1 (86.13\%) than the iron-bryostatin-1 complex (98.93\%), or on average the medicinal efficacy for inhibiting cancer cell growth was diminished by approximately 13 percent when complexed with the iron cation. In some cell lines, the efficacy of both compounds were very similar, such as the non-small cell lung cancer NCI-H23 (bryostatin-1 100\%; iron-bryostatin-1 99.77\%), ovarian cancer IGROV1 (bryostatin-1 85\%; ironbryostatin-1 84.46\%), prostate cancer DU-145(bryostatin-1 97\%; iron-bryostatin-1 97.64\%), and breast cancer BT-549 (bryostatin-1 97\%; iron-bryostatin-1 96.24\%). Results from three central nervous cancer cell lines were similar between bryostatin-1 and iron-bryostain-1, however ironbryostatin-1 slightly outperformed bryostatin-1 in two cell lines: SF-268 (103\%; 102.78\%), U251 (98\%; 97.32\%), SF-539 (98\%; 98.25\%). In two cell lines, percent growths were very similar to the two compounds, with iron-bryostatin-1 being slightly more efficacious. Ovarian cancer cell line OVCAR-5 resulted with a 99.87 percent growth with bryostatin-1 complexed with iron compared to 101 percent growth without iron, and breast cancer cell line MCF7 resulted with a 97.48 percent growth with bryostatin-1 complexed with iron compared to 100 percent growth without iron. In other cell lines, there was a more drastic decrease in efficacy when complexing bryostatin-1 with iron, such as colon cancer cell line COLO205 which resulted with nearly a 50 percent increase of growth after adding the metal ion $(53 \% ; 102.93 \%)$.

Results from a computational study have demonstrated that the natural bond formation of iron and bryostatin- 1 induces parameters that are considered to increase delivery and/or efficacy in medicinal applications. For instance, the computational data suggested that the dipole moments, $\log$ P and TPSA values can increase or decrease for all 20 bryostatin forms when 
complexed to iron, which are important parameters outlined by Lipinski's Rule of Five. Computed surface area and molecular volume were shown to decrease slightly after complexation to the cation, indicating contraction of the structure which could potentially translate to easier transport past cell membranes and improved delivery. Bryostatin is susceptible to degradation through hydrolysis of ester bonds, however the binding of iron to the oxygen molecules of the compound improves stability by lowering the chances of a nucleophilic attack. Increasing the charge of the molecule by $+1,+2$, or +3 can increase water solubility, an important parameter for improving pharmaceutical agent delivery. ${ }^{36}$ Although the computational data suggested that iron compounded with bryostatin-1 may increase efficacy of the drug in vivo based on Lipinksi's Rule of Five and other factors ${ }^{36}$, in vitro cell line data presented in this study demonstrated a decrease in efficacy. Similar results were also found in another study by Manning et al. ${ }^{41}$ using iron-taxol. Computational studies of the iron-taxol complex have demonstrated that binding to iron could increase stability and water solubility as well, giving evidence that the added cation could improve performance of the anti-cancer drug. However when tested against NCI's 60 cell line panel, iron-taxol was on average over an order of magnitude less efficacious in inhibiting cell growth than pure taxol. ${ }^{41}$

Bryostatin-1 is a macrolid molecule with a large ring that has oxygen molecules pointing inward, capable of binding a cation such as iron. The metal-ligand complexation of bryostatin-1 to iron is characterized by a hexavalent geometry dominated by six Fe-O bonds forming an octahedral geometry. The sodium-bryostatin- 1 complex $(927 \mathrm{~g} / \mathrm{mol})$ is the most common form of bryostatin-1 measured when performing extractions. Figures 5-7 were constructed using Spartan'14 molecular modeling software to provide an image of the uncomplex bryostatin-1 


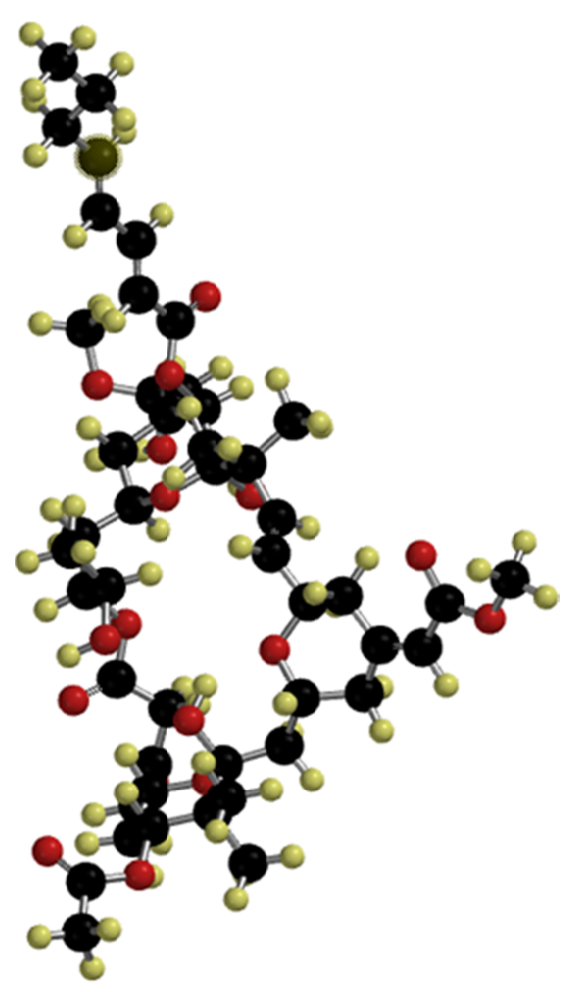

Figure 5. Computational technique used to model an uncomplexed bryostatin-1 molecule $(224.7532 \mathrm{~kJ} / \mathrm{mol})$. 


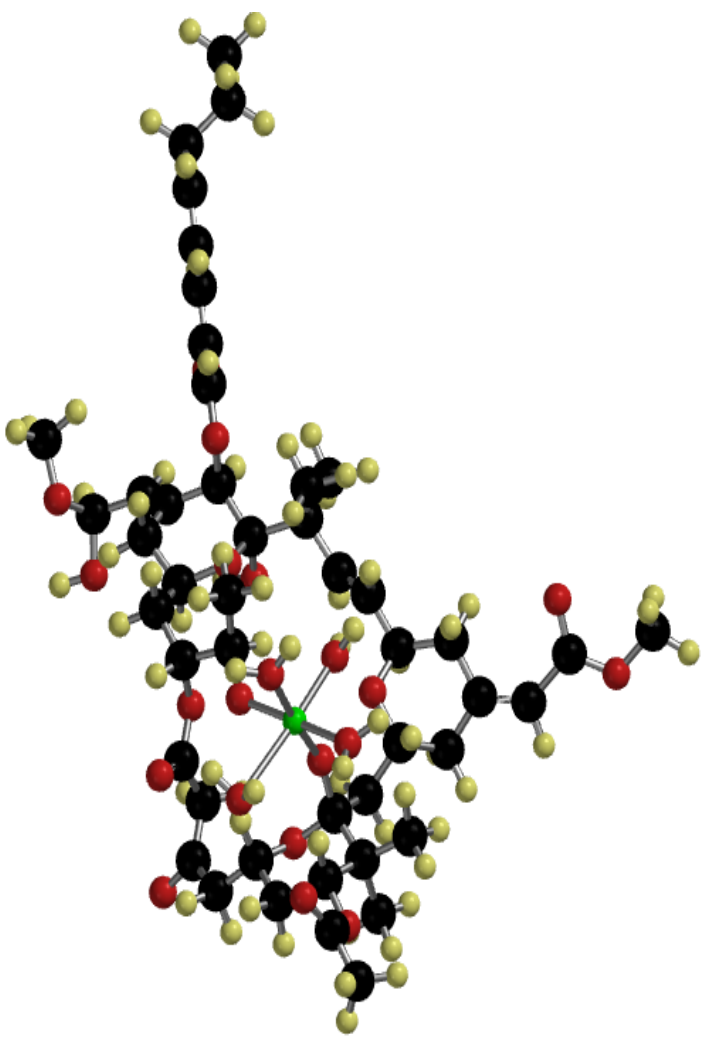

Figure 6. Bryostatin-1 complexed to iron with four of the six coordination sites occupied by water molecules $\left[\mathrm{Fe}\left(\mathrm{H}_{2} \mathrm{O}\right)_{4}\right.$-bryostatin-1] $(-46.3064 \mathrm{~kJ} / \mathrm{mol})$. 


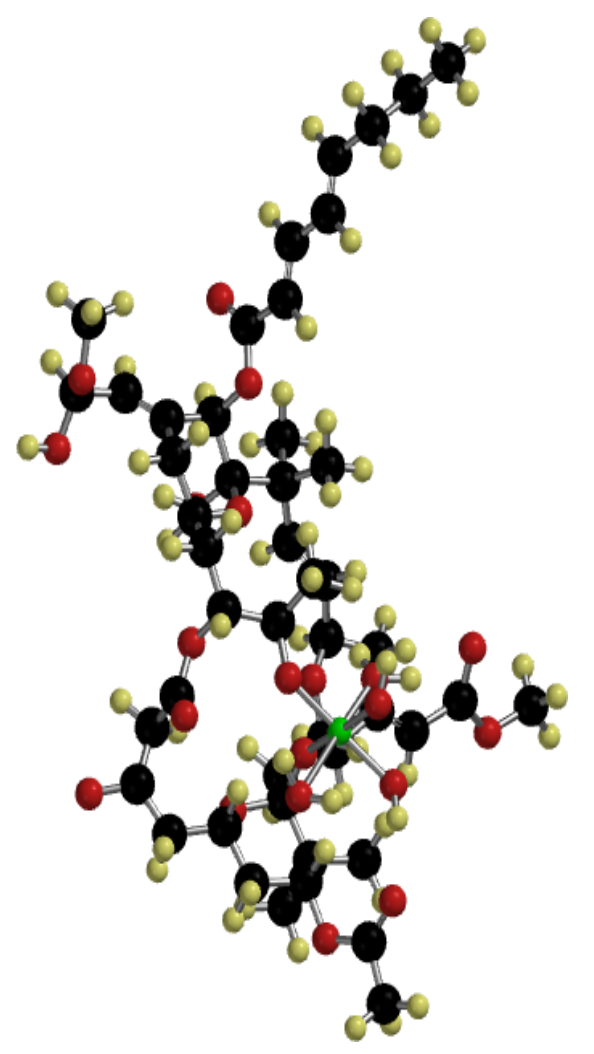

Figure 7. Bryostatin-1 complexed to iron with two water molecules and two hydroxides in the inner sphere of the hexavalent complex $\left[\mathrm{Fe}\left(\mathrm{H}_{2} \mathrm{O}\right)_{2}(\mathrm{OH})_{2}\right.$-bryostatin-1] $(-43.0118 \mathrm{~kJ} / \mathrm{mol})$. 
molecule, bryostatin-1 complexed to iron with four coordination sites occupied by water molecules, and iron complexed to bryostatin-1 with two water molecules and two hydroxides in the inner sphere of the hexavalent complex. ${ }^{42}$ Adding iron to the complex lowers the energy, indicating that the metal-ligand complex is more stable than the molecule itself.

A possible explanation for the decrease in medicinal efficacy of iron-bryostatin-1 could be attributed to the formation of aggregates resulting from an organo-metallic complex. At a $\mathrm{pH}$ between seven and eight, iron can form an oxide and hydroxide complex at millimolar and micromolar concentrations. While iron can strongly bond the oxygen atoms in a bryostatin complex, it is hexavalent and can bind other species as well that produce nanometer sized aggregates in solution. The hexavalent cation can form a complex such as $\left[\mathrm{Fe}-\text { bryostatin- }(\mathrm{OH})_{3}\right]_{\mathrm{n}}$ where $\mathrm{n}>1$. These aggregates can minimize the medicinal activity of the complex by blocking the medicinally active components of the structure.

$$
\begin{aligned}
& \mathrm{Fe}^{3+}(\mathrm{aq})+\text { Bryostatin }(\mathrm{aq})+2 \mathrm{H}_{2} \mathrm{O}(\mathrm{l}) \rightarrow\left[\mathrm{Fe}(\mathrm{OH})_{3}-\text { Bryostatin }^{+}\right. \\
& \mathrm{Fe}^{+3}(\mathrm{aq})+3 \mathrm{H}_{2} \mathrm{O}(\mathrm{l}) \rightarrow \mathrm{Fe}(\mathrm{OH})_{3}(\mathrm{~s}) \\
& \mathrm{K}_{\mathrm{sp}}=4 \times 10^{-38}
\end{aligned}
$$

Iron hydroxide and iron oxide suspended in solution as nanoparticles have been used in drug delivery. For example, they have been used as a drug delivery mechanism for paramagnetic shift reagents in Magnetic Resonance Imaging to monitor brain tumors. ${ }^{43}$ The metal oxide and/or metal hydroxide nanoparticle is also used as part of different flocculation processes that are aimed at encompassing and precipitating organic species. ${ }^{44}$

A study by Manning et al. ${ }^{45}$ evaluated cell line studies of taxol complexed with a different cation, copper(II), as the carrier. These results improved growth inhibition of cancer 
cells compared to that of the pure drug. For example, $\mathrm{Cu}$ (II)-taxol resulted with forty-six cell lines with $\mathrm{GI}_{50}$ values lower than $10^{-8} \mathrm{M}$ while taxol resulted with twenty-seven cell lines under

this concentration, indicating improvement against nineteen different forms of cancer. Complexing taxol with iron resulted with no $\mathrm{GI}_{50}$ values less than $10^{-8} \mathrm{M} .{ }^{45}$

Bryostatin has been continuously tested for its efficacy to treat various forms of cancer, $\mathrm{HIV}, \mathrm{AD}$, and stroke side effects although obtaining the compound is costly and technically trying. In this study, iron-bryostatin-1 was produced by a pharmaceutical aquaculture technique followed by an extraction process developed by Manning et al. ${ }^{34}$ Comparison of the original ${ }^{13} \mathrm{C}$ and ${ }^{1} \mathrm{H}$ NMR spectra to those of the iron-bryostatin-1 complex and the illustration of peaks shifting from their relative ranges on the graphs suggests that the presence of iron resulted in structural changes in the binding preference of oxygen atoms found in bryostatin-1. The NCI's 60 cell line panel demonstrated that the medicinal efficacy of iron-bryostatin-1 was on average lower than pure bryostatin-1 by approximately 13 percent. While this study demonstrated a decrease in medicinal efficacy with natural iron complexation to bryostatin-1, it does represent a method for obtaining natural iron-bryostatin-1 compounds for pharmaceutical research. Efforts in this lab are now focused on obtaining pure bryostatin-1 using this technique for additional pharmaceutical research. 


\section{Acknowledgements}

We would like to thank the Developmental Therapeutics Program, Division of Cancer Treatment and Diagnosis, National Cancer Institute (http://dtp.cancer.gov) for providing the preclinical trial data for this research. We would like to thank the VSU Major Equipment fund, VSU-QEP (Dr. Jim LaPlant, Dr. Michael Black), VSU Interlibrary Loan (Denise Montgomery), FRSG grant (Anita Bosch), and the VSU Chemistry department (Melissa Nolley, Jim Baxter) for supporting different aspects of this work. We would like to thank the VSU-IT division, particularly David Pierce, Annon Beepath and Joe Newton for their expertise with computer issues and modeling software. A portion of this work was performed at the National High Magnetic Field Laboratory, which is supported by National Science Foundation Cooperative Agreement NSF Grant Number to DMR-11-57490. We would also like to thank the Florida State University Coastal \& Marine Lab and its Director Dr. Felicia Coleman for use of their facilities. The Alligator Point Yacht marina (Alligator Point, FL) is thanked for access to the Alligator Point Harbor. We also thank Gulf Specimen Marine Lab and the Rudloe family for inspiring this bryostatin research. This work was partially inspired by National Institutes of Health and the National Institute of Allergy and Infectious Diseases, Contract No. HHSN272201100009I. 


\section{$\underline{\text { References }}$}

1. Pettit, G.R. J. Nat. Prod. 1996, 59, 812.

2. Pettit, G. R.; Herald, C.L.; Doubek, D.L.; Herald, D.L.; Arnold, E.; Clardy, J. J. Am. Chem. Soc. 1982, 104, 6846.

3. Hale, K.J.; Manaviazar, S. Chem Asian J. 2010, 5, 704.

4. Davidson, S.K.; Allen, S. W.; Lim, G.E.; Anderson, C.M.; Haygood, M.G. Appl. Environ. Microbiol. 2001, 67, 10, 4531.

5. Kortmansky, J.; Schwartz, G.K. Cancer Invest. 2003, 21, 924.

6. Sun, M-K.; Alkon, D.L. CNS Drug Rev. 2006, 12, 1.

7. Morgan Jr., R.J.; Leong, L.; Chow, W.; Gandara, D.; Frankel, P.; Garcia, A.; Lenz, H.J.; Doroshow, J.H. Invest New Drugs. 2012, 30, 723.

8. Blackhall, F.H.; Ranson, M.; Radford, J.A.; Hancock, B.W.; Soukop, M.; McGown, A.T.; Robbins, A.; Halbert, G.; Jayson, G.C. Br. J. Cancer. 2001, 84, 465.

9. Peterson, A.C.; Harlin, H.; Karrison, T.; Vogelzang, N.J.; Knost, J.A.; Kugler, J.W.; Lester, E.; Vokes, E.; Gajewski, T.F.; Stadler, W.M. Invest New Drugs. 2006, 24, 141.

10. Madhusudan, S.; Protheroe, A.; Propper, D.; Han, C.; Corrie, P.; Earl, H.; Hancock, B.; Vasey, P.; Turner, A.; Balkwill, F.; Hoare, S.; Harris, A.L. Br. J. Cancer. 2003, 89, 1418.

11. Ajani, J.A.; Jiang, Y.; Faust, J.; Chang, B.B.; Ho, L.; Yao, J.C.; Rousey, S.; Dakhil, S.; Cherny, R.C.; Craig, C.; Bleyer, A. Invest New Drugs. 2006, 24, 353.

12. Etcheberrigaray, R.; Tan, M.; Dewachter, I.; Kuipéri, C.; Van der Auwera, I.; Wera, S.; Qiao, L.; Bank, B.; Nelson, T.J.; Kozikowski, A.P.; Leuven, F.V.; Alkon, D.L. Proc. Natl. Acad. Sci. U.S.A. 2004, 101, 11141.

13. Hongpaisan, J.; Sun, M-K.; Alkon, D.L. J. Neurosci. 2011, 31, 630.

14. Denvir, J.; Neitch, S.; Fan, J.; Niles, R.M.; Boskovic, G.; Schreurs, B.G.; Primerano, D.A.; Alkon, D.L.; J. Alzheimers Dis. 2015, 46, 483.

15. Sun, M-K.; Hongpaisan, J.; Nelson, T.J.; Alkon, D.L. Proc. Natl. Acad. Sci. U.S.A. 2008, $105,13620$.

16. Sun, M-K.; Hongpaisan, J.; Alkon, D.L. Proc. Natl. Acad. Sci. U.S.A. 2009, 106, 14676.

17. Tan, Z.; Turner, R.C.; Leon, R.L.; Li, X.; Hongpaisan, J.; Zheng, W.; Logsdon, A.F.; Naser, Z.J.; Alkon, D.L.; Rosen, C.L.; Huber, J.D. Stroke. 2013, 44, 3490.

18. Mehla, R.; Bivalkar-Mehla, S.; Zhang, R.; Handy, I.; Albrecht, H.; Giri, S.; Nagarkatti, P.; Nagarkatti, M.; Chauhan, A. PloS One. 2010, 5, 1.

19. DeChristopher, B.A.; Loy, B.A.; Marsden, M.D.; Schrier, A.J.; Zack, J.A.; Wender, P.A. Nat Chem. 2012, 4, 705.

20. Mendola, D. Biomol. Eng. 2003, 20, 441.

21. Dahms, H.W.; Gao, Q.F.; Hwang, J.S. Aquaculture. 2007, 265, 169.

22. Evans, D.A.; Carter, P.H.; Carreira, E.M.; Charette, A.B.; Prunet, J.A.; Lautens, M. J. Am. Chem. Soc. 1999, 121, 7540.

23. Ohmori, K.; Ogawa, Y.; Obitsu, T.; Ishikawa, Y.; Nishiyama, S.; Yamamura, S. Angew. Chem. Int. Ed. 2000, 39, 2290.

24. Wender, P.A.; Schrier, A.J. J. Am. Chem. Soc. 2011, 133, 9228.

25. Trost, B.M.; Dong, G. Nature. 2008, 456, 485.

26. Lu, Y.; Woo, S.K.; Krische, M.J. J. Am. Chem. Soc. 2011, 133, 13876.

27. Keck, G.E.; Poudel, Y.B.; Cummins, T.J.; Rudra, A.; Covel, J.A. J. Am. Chem. Soc.2011, 133, 744. 
28. Wender, P.A.; DeBrabander, J.; Harran, P.G.; Jimenez, J-M.; Koehler, M.F.T.; Lippa, B.; Park, C-M.; Siedenbiedel, C.; Pettit, G.R. Proc. Natl. Acad. Sci. U.S.A. 1998, 95, 6624.

29. Wender, P.A.; Loy, B.A.; Schrier, A.J. Isr. J. Chem. 2011, 51, 453.

30. DeChristopher, B.A.; Fan, A.C.; Felsher, D.W.; Wender, P.A. Oncotarget. 2012, 3, 58.

31. Tang, X.; Liang, X. Chem. Biol. Drug Des. 2013, 81, 311.

32. Santhosh, P.B.; Ulrih, N.P. Cancer Lett. 2013. 336, 8.

33. Manning, T.J.; Land, M.; Rhodes, E.; Chamberlin, L.; Rudloe, J.; Phillips, D.; Lam, T.T.; Purcell, J.; Cooper, H.J.; Emmett, M.R.; Marshall, A.G. Nat. Prod. Res. 2005, 19, 467.

34. Manning, T.; Jones, R.; Little, B.; Lannon, C.; Kean, G.; Nienow, J. Technology Innovation 2010, 12, 171.

35. Manning, T.J.; Rhodes, E.; Land, M.; Parkman, R.; Sumner, B.; Lam, T.T.; Marshall, A.G.; Phillips, D. Nat. Prod. Res. 2006, 20, 611.

36. Manning, T.J.; Thomas, J.; Osiro, S.; Smith, J.; Abadi, G.; Noble, L.; Phillips, D. Nat. Prod. Res. 2008, 22, 399.

37. Cullen, L.E.; Macfarlane, C. Tree Physiology. 2005. 25, 563.

38. Pettit, G.R.; Herald, C.L.; Kamano, Y.; Gust, D.; Aoyagi, R. J. Nat. Prod. 1983, 46, 528.

39. Pettit, G.R., Herald, C.L., Kamano, Y. European Patent 85305679.4, 1985.

40. NCI DTP PUBLIC COMPARE database (NSC = 339555). https://dtp.cancer.gov/compareweb-public_compare

41. Manning, T.; Hoover, W.; Kean, G.; Thomas, J.; McLeod, B.; Ogden, M.; Wilbanks, W.; Abadi, G.; Phillips, D. Technology Innovation. 2010, 12, 153.

42. Spartan, version 1.1.4; Wavefunction INC and Q-Chem: Irvine, CA, 2014 (accessed $11 / 15 / 15)$

43. Chertok, B.; Moffat, B.A.; David, A.E.; Yu, F.; Bergemann, C.; Ross, B.D.; Yang, V.C. Biomaterials. 2008, 29, 487.

44. Zrinyi, M.; Kabai-Faix, M.; Horkay, F.; Fuhos, S. Langmuir. 1993, 9, 71.

45. Manning, T.J.; Phillips, D.; Wylie, G.; Bythell, B.; Clark, C.; Ogburn, R.; Ledwitch, K.; Collis, C.; Patterson, S.; Lasseter, L. Bioorg. Med. Chem. Lett. 2013, 24, 371. 